\title{
REPARACIONES EN LA
}

\section{CORTE INTERAMERICANA}

\section{DE DERECHOS HUMANOS*}

\author{
Juan Guillermo Cubides Molina***
}

\author{
REPARATIONS IN THE INTER-AMERICAN \\ COURT OF HUMAN RIGHTS
}

AS REPARAÇÕES NA CORTE INTERAMERICANA

DE DIREITOS HUMANOS

Fecha de recepción: 02 de marzo de 2016.

Fecha de aprobación: 17 de mayo de 2016.

\section{Sugerencia de citación:}

Cubides Molina, J.M. (2016). Reparaciones en la Corte Interamericana de Derechos Humanos. Razón Crítica, 1, 52-91 doi: http://dx.doi.org/10.21789/25007807.1137

* El artículo es resultado parcial de investigación para optar al título de Magíster en Derecho en la Universidad Nacional de Colombia, focalizado en las modalidades de reparación adoptadas por la Corte IDH y el Consejo de Estado colombiano. Trabajo de investigación dirigido por el doctor Édgar Hernán Fuentes Contreras.

** Abogado de la Universidad Nacional de Colombia y Especialista y Magíster en Derecho Administrativo de la misma. Becario de la Asociación Universitaria Iberoamericana de Postgrados para el Máster Oficial en Derecho Constitucional en la Universidad de Sevilla. Actualmente, estudiante en desarrollo del trabajo final del Máster Oficial en Derecho Constitucional de la Universidad de Sevilla (España). Correo electrónico: jgcubidesm@gmail.com. 


\section{RESUMEN}

La Corte Interamericana de Derechos Humanos -en adelante Corte IDH-, a través de su jurisprudencia, ha estipulado las modalidades en que se expresan las reparaciones decretadas en favor de las víctimas de violaciones de derechos humanos a fin de resarcir el daño causado a las mismas. Modalidades que han sido sistematizadas principalmente por el profesor chileno Claudio Nash Rojas y que, en el presente documento, se expondrán de manera descriptiva, en complemento con la jurisprudencia de la misma Corte IDH y los aportes de otros autores, evidenciando los progresos y a la vez aspectos pendientes por desarrollar en procura de una reparación real.

PALABRAS CLAVE:

reparaciones, reparaciones materiales, reparaciones inmateriales, víctimas. 


\begin{abstract}
The Inter-American Court of Human Rights, hereafter IDH-Court, through its jurisprudence, has stipulated the modalities of reparation ordered in favor of victims of human rights violations in order to compensate the damage caused to them. The Chilean Professor Claudio Nash Rojas mostly systematized these modalities. This paper will present them descriptively, along with the jurisprudence of the IDH-Court and contributions from other authors, showing the advancements and questions to solve in search of a real reparation.
\end{abstract}

\title{
KEYWORDS:
}

reparations, material reparations, intangible reparations, victims. 


\section{RESUMO}

A Corte Interamericana de Direitos Humanos, doravante Corte IDH, através da sua jurisprudência, estipulou as modalidades de reparação ordenadas em favor das vítimas de violações dos direitos humanos, a fim de compensar os danos causados a eles. Estas modalidades foram principalmente sistematizadas por o professor chileno Claudio Nash Rojas. Neste trabalho, eles são apresentadas de forma descritiva, juntamente com a jurisprudência da Corte IDH e as contribuições de outros autores, mostrando os avanços e as questões pendentes para desenvolver, em busca de reparações reais.

\section{PALAVRAS-CHAVE:}

reparações, reparações materiais, reparações intangível, vítimas. 


\section{N T R O D U C C I Ó N}

Las modalidades de reparación sistematizadas a partir de la jurisprudencia de la Corte IDH reflejan el compromiso de dicho Tribunal por concretizar, por hacer real y efectivo el derecho a la reparación de las víctimas de violaciones de derechos humanos. Dichas reparaciones van desde lo material hasta lo inmaterial, desde el reconocimiento de indemnizaciones en dinero hasta la celebración de actos públicos de desagravio, así como la efectiva investigación, juzgamiento y sanción de los autores de las violaciones.

A dicha sistematización ha dedicado gran parte de su actividad profesional el profesor chileno Claudio Nash Rojas, autor del libro "Las Reparaciones ante la Corte Interamericana de Derechos Humanos", que en las dos ediciones del mismo recoge la jurisprudencia de dicho Tribunal en materia de reparaciones desde el año 1988 hasta el año 2007.

Y si bien Nash no ha vuelto a actualizar su obra con posterioridad a lo establecido por la Corte IDH hasta 2007, no significa que haya abandonado su interés al respecto. Prueba de ello es el curso que impartió en el Campus Virtual de la Fundación Gregorio Peces-Barba - Universidad Carlos III de Madrid, durante el mes de julio de 2015, "Las modalidades de reparación en la Corte Interamericana de Derechos Humanos”, para el cual elaboró tres lecciones en donde, además de exponer y "actualizar" las modalidades de reparación según la jurisprudencia de dicha Corporación con posterioridad al año 2007, abordó los principales desafíos de las mismas (Nash, 2015).

En consideración de lo anterior, como marco referencial, el presente artículo sigue el trabajo académico del profesor 
Nash junto con la jurisprudencia de la Corte IDH, aplicando una metodología principalmente descriptiva de las modalidades de reparación de dicho Tribunal, sistematizadas por aquel, amén de más de veinte años de trabajo intelectual del autor austral sobre la materia, adoptando la forma en que él mismo estructuró el estudio de dichas modalidades en sus escritos más actuales, las lecciones del curso virtual "Las modalidades de reparación en la Corte Interamericana de Derechos Humanos”, en complemento con lo que indicado por otros autores al respecto.

Así las cosas, la exposición de lo que ha establecido la Corte IDH, respecto de cada una de las modalidades de reparación, es el objetivo principal del artículo por el que trasiega el lector, advirtiendo que el mismo es el resultado de una investigación inicial de Maestría y, por lo mismo, esencialmente se dedica a describir ítems muy concretos, al tiempo que identifica preliminarmente aspectos que podrían requerir mayor desarrollo y concreción por parte de la jurisprudencia de la Corte IDH y que darían lugar a un escrito posterior. 


\section{El derecho-deber a la reparación según la jurisprudencia de la Corte Interamericana de Derechos Humanos}

El derecho a la reparación surge como consecuencia de la responsabilidad atribuible a alguien, a un sujeto que no observó sus obligaciones principales, a efectos de este documento, el Estado. En consecuencia, la reparación es un derecho para quién resultó afectado y también un deber que recae en cabeza del responsable del incumplimiento. Tiene entonces la reparación la doble connotación de derechodeber que en últimas resulta ser dos caras de la misma moneda (Calderón, s.f., p. 157).

El deber de reparar debe interpretarse y garantizarse como lo dispone el Derecho Internacional, según ha señalado la doctrina jurídica correspondiente, del siguiente modo:

La obligación de reparar las violaciones a los derechos humanos contenida en el artículo 63.1 de la Convención Americana sobre Derechos Humanos [...] recoge una norma consuetudinaria de derecho internacional, según la cual, al producirse un hecho ilícito imputable a un Estado surge inmediatamente la responsabilidad internacional de éste por la violación de una norma internacional, con el consecuente deber de reparación y de hacer cesar las consecuencias de esa violación. De esta manera, las reparaciones ordenadas por la Corte imponen obligaciones de derecho internacional, cuyo contenido no puede ser modificado ni su cumplimiento suspendido por el Estado obligado, invocando para ello disposiciones de su derecho interno. Los modos específicos de reparar varían según el daño producido (Saavedra, s.f.).

[...] en efecto, en las últimas décadas se han consolidado imperativos jurídicos internacionales que protegen los derechos de las víctimas de violaciones masivas de derechos humanos ocurridas en la etapa previa a las transiciones y que buscan impedir que hechos como los acaecidos vuelvan a suceder. Estos derechos se concretan en el conocimiento de la verdad de los hechos ocurridos, en la obtención de una reparación por concepto de ello y en la judicialización y responsabilidad del culpable de los crímenes (Uprimny, 2005, p. 13). 
La Convención Americana de Derechos Humanos, en su artículo 63.1, es muy clara acerca del deber de reparar:

Cuando decida que hubo violación de un derecho o libertad protegidos en esta Convención, la Corte dispondrá que se garantice al lesionado en el goce de su derecho o libertad conculcados. Dispondrá asimismo, si ello fuera procedente, que se reparen las consecuencias de la medida o situación que ha configurado la vulneración de esos derechos y el pago de una justa indemnización a la parte lesionada.

En el caso "Aloeboetoe y Otros vs. Surinam", refiriéndose explícitamente al precitado artículo 63.1, la Corte IDH se pronunció de la siguiente manera:

Este artículo constituye una norma consuetudinaria que es, además, uno de los principios fundamentales del actual derecho de gentes tal como lo han reconocido esta Corte [...]

La obligación contenida en el artículo 63.1 de la Convención es de derecho internacional y éste rige todos sus aspectos como, por ejemplo, su extensión, sus modalidades, sus beneficiarios, etc. Por ello, la presente sentencia impondrá obligaciones de derecho internacional que no pueden ser modificadas ni suspendidas en su cumplimiento por el Estado obligado invocando para ello disposiciones de su derecho interno (Aloeboetoe y Otros vs. Surinam, 10 de septiembre de 1993, pp. 43-44).

Se puede concluir, en punto del deber de reparar que tienen los Estados cuando sobre ellos recae responsabilidad en el Sistema Interamericano de Protección de Derechos Humanos, que:

1) La reparación es un auténtico derecho-deber, derecho para el afectado, deber para el Estado responsable de la violación.

2) Las modalidades de reparación a las que tienen derecho las víctimas de violaciones a los derechos humanos concretizan ese deber de reparar que recae en el Estado infractor.

3) El deber de reparar se encuentra establecido claramente por la Convención Americana de 
Derechos Humanos como obligación del Estado infractor.

4) “[1]a obligación de reparación establecida por los tribunales internacionales se rige por el Derecho Internacional en todos sus aspectos: su alcance, su naturaleza, sus modalidades, y la determinación de los beneficiarios, nada de lo cual puede ser modificado por el Estado obligado invocando para ello disposiciones de su Derecho interno" (Faúndez, 1999, p. 497).

Conforme al mandato de la Convención Americana de Derechos Humanos, cuando un Estado es responsable por la inobservancia de dicho instrumento internacional, surge en cabeza de dicho sujeto la obligación de reparar las consecuencias de la conculcación de derechos humanos (Faúndez, 1999, p. 497).

[...] en caso que se concluya que ha habido una violación de los derechos humanos, la función de la Corte no consiste únicamente en determinar el monto de la indemnización a pagar sino que, sobre todo, en indicar las medidas concretas que debe adoptar el Estado infractor para reparar las consecuencias de su acto ilícito; se trata de dos consecuencias de la infracción que están en relación de género a especie, siendo la indemnización sólo una de las muchas formas que puede asumir la reparación, pero no la única. Con mucha razón, se ha observado que los términos del art. 63 № 1 de la Convención abren a la Corte un horizonte bastante amplio en materia de reparaciones (Faúndez, 1999, pp. 497-498).

En el siguiente acápite se obtendrá un panorama general de las modalidades de reparación que ha establecido en su jurisprudencia la Corte IDH, el estándar de reparaciones de ese Tribunal Internacional. El lector se encontrará con los aspectos esenciales de dicho derecho, recopilados y explorados en detalle en la obra del profesor Claudio Nash, que sustancialmente coinciden con el conjunto de criterios que Theo van Boven, experto independiente de las Naciones Unidas, desarrolló para reparar graves violaciones de derechos humanos, y que la Asamblea General de las Naciones 
Unidas, en el año 2005, promulgó como "Principios y directrices básicos sobre el derecho de las víctimas de violaciones manifiestas de las normas internacionales de derechos humanos y de violaciones graves de derechos humanos y de violaciones graves del derecho internacional humanitario a interponer recursos y obtener reparaciones", reconociendo la restitutio in integrum, la indemnización, las medidas de rehabilitación, las medidas de satisfacción y las garantías de no repetición, como tipos de reparaciones (Núñez \& Zuluaga, 2012, pp. 211-212).

\section{Las modalidades DE reparación en la jurisprudencia de la Corte Interamericana de Derechos Humanos. La obra del profesor Claudio Nash}

Es prolífica la doctrina jurídica desarrollada por la Corte IDH respecto del derecho a la reparación en tanto "[...] ha venido elaborando la temática de las reparaciones de violaciones de derechos humanos a partir de la integralidad de la personalidad de las víctimas [...] de modo a atender sus necesidades y reivindicaciones, y buscar su plena rehabilitación” (López, 2009, p. 314), por ello, "la reparación de violaciones a los derechos humanos puede abarcar una serie de matices que dependen de la gravedad de la violación, motivo por el cual la Corte IDH en su jurisprudencia ha adoptado -dependiendo del casodiferentes medidas de reparación” (López, 2009, p. 321).

Si las modalidades que adopta la Corte IDH concretizan y efectivizan el derecho a la reparación de las víctimas, cabe preguntarse ¿cuáles son esas modalidades?

El diccionario de la Real Academia de la Lengua Española define la palabra "modalidad" como modo de ser o de manifestarse algo. En ese entendido se puede entender que modalidad de reparación es la manera de ser o la manera como se manifiesta el derecho a la reparación. 
Sin embargo, no se habla de modo de reparación, sino de modalidades, en plural, denotando semánticamente que no existe un solo modo de ser, de manifestarse, de concretarse el derecho a la reparación, sino que existen varias formas de hacer realidad el mismo, las cuales se han agrupado bajo la denominación "modalidades de reparación".

El profesor chileno Claudio Nash, sistematiza las modalidades de la reparación en la Corte IDH en las siguientes: restitución, compensación, satisfacción y garantías de no repetición (Nash, 2015). Precisamente, "[1]a reparación es el término genérico que comprende las diferentes formas como un Estado puede hacer frente a la responsabilidad internacional en que ha incurrido (restitutio in integrum, indemnización, satisfacción, garantías de no repetición, entre otras)" (Loayza Tamayo vs. Perú, 27 de noviembre de 1998, p. 85).

\section{i. Las reparaciones materiales}

\section{a. La regla de la restitutio in integrum}

Catalina Botero Marino y Esteban Restrepo Saldarriaga (2006, pp. 77-78), teniendo en cuenta los principios y directrices básicos sobre el derecho de las víctimas de violaciones de las normas internacionales de derechos humanos y del derecho internacional humanitario a interponer recursos y obtener reparaciones, sostienen que:

[...] la restitución, también conocida como restitutio in integrum, persigue "devolver a la víctima a la situación anterior a la violación" y comprende, entre otras cuestiones, "el restablecimiento de la libertad, los derechos legales, la situación social, la identidad, la vida familiar y la ciudadanía de la víctima, el regreso a su lugar de residencia, la reintegración en su empleo y la devolución de sus propiedades" (principio 21). De otro lado, los Estados están obligados a indemnizar a las víctimas de violaciones de los derechos humanos en forma "apropiada y proporcional a la violación y a las circunstancias de cada caso" y a los perjuicios económicos derivados de la vulneración de que se trate, entre los cuales se destacan el daño físico o mental, la pérdida de oportunidades, 
los daños materiales y la pérdida de ingreso, el daño a la reputación o dignidad y los gastos incurridos por la víctima en materia de asistencia jurídica y servicios médicos (principio 22). En cuanto a la rehabilitación, los principios antes señalados determinan que ésta "ha de incluir, según proceda, la atención médica y psicológica, así como servicios jurídicos y sociales" (principio 23).

Con todo, en un ejercicio de simple valoración de hechos que configuren violaciones de derechos humanos, se puede concluir que, las más de las veces, resulta imposible devolver a la víctima a la situación anterior a la violación, restituirle en toda su integridad el derecho conculcado. Considérese apenas el caso de una ejecución extra judicial cometida por agentes del Ejército Nacional. ¿Acaso puede devolver el Estado el derecho a la vida a quien fue ejecutado extra judicialmente?

Ante ese panorama, en la sentencia del caso "Blake vs. Guatemala”, la Corte IDH, precisamente por la ejecución extrajudicial de un periodista norteamericano en territorio guatemalteco, al tornarse imposible la implementación de una restitución in integrum, refirió que puede haber otras modalidades que se adecuen al caso concreto, que en todo caso deben ser posibles, suficientes y adecuadas.

La regla de la restitutio in integrum se refiere a una de las formas de reparación de un acto ilícito internacional (cfr. Usine de Chorzów, fond, supra 33, p. 48), pero no es la única modalidad de reparación, porque puede haber casos en que la restitutio no sea posible, suficiente o adecuada. La indemnización corresponde en primer término a los perjuicios sufridos por la parte lesionada, y comprende, como esta Corte ha expresado anteriormente, tanto el daño material como el moral (Blake vs. Guatemala, 22 de enero de 1999: 145). (Negrita y subrayas fuera del texto original).

Pues bien, cuando no se pueda restituir a la víctima de manera plena en sus derechos, Nash (2015, p. 3), retomando a la Corte IDH, evidencia que, en garantía del derecho a la reparación, quedan abiertos otros caminos, adquiriendo este concepto un carácter "amplio y plural": 
[...] De no ser esto factible (la plena restitución), como ocurre en la mayoría de los casos, el Tribunal determinará medidas para garantizar los derechos conculcados, reparar las consecuencias que las infracciones produjeron y establecer una indemnización que compense los daños ocasionados. Por tanto, la Corte ha considerado la necesidad de otorgar diversas medidas de reparación, a fin de resarcir los daños de manera integral, por lo que además de las compensaciones pecuniarias, las medidas de restitución, satisfacción y garantías de no repetición tienen especial relevancia por los daños ocasionados (Chocrón vs. Venezuela, 01 de julio de 2011).

Entonces, no sólo se debe tener en consideración la “justa indemnización” del artículo 63.1 de la Convención Americana de Derechos Humanos como una medida de reparación de carácter puramente pecuniario, pues la misma comprende este aspecto pero lo desborda, siendo comprensiva la indemnización tanto del daño material (daño emergente y lucro cesante) como del daño inmaterial o daño moral (Nash, 2009, pp. 42-43).

El daño material ha sido entendido por la Corte como "la pérdida o detrimento de los ingresos de la víctima y, en su caso, de sus familiares, y los gastos efectuados como consecuencia de los hechos en el caso sub judice” y, en este sentido, la indemnización compensatoria debe estar destinada a "compensar las consecuencias patrimoniales de las violaciones declaradas en la presente sentencia”. Para poder fijar el monto, la Corte tendrá en consideración una serie de elementos, "el acervo probatorio, la jurisprudencia del propio Tribunal y los argumentos de las partes (Nash, 2009, p. 41)1. (Negrita y subrayas fuera del texto original).

1. Las citas del texto de Nash (2009) corresponden al caso López Álvarez vs. Honduras, 01 de febrero de 2006, p. 192.
La anterior es la definición clásica del daño material, conceptualizado desde el daño directo (Nash, 2015, p. 4). No obstante, la Corte IDH ha considerado en su jurisprudencia otro elemento a tener en cuenta en el daño directo: las consecuencias de carácter pecuniario que tengan un nexo causal con los hechos del caso, ampliando así los factores que se deben tomar en consideración para fijar las medidas de reparación correspondientes (Nash, 2009, p. 42).

En síntesis, para la Corte IDH, los elementos del daño 
material, como daño directo que debe ser reparado fijando un monto indemnizatorio que compense las consecuencias patrimoniales de las violaciones sufridas, son los siguientes, según Nash (2009, p. 42): “1. Pérdida o detrimento de los ingresos de la víctima (lucro cesante); 2. Gastos efectuados con motivo de los hechos (daño emergente); 3. Consecuencias de carácter pecuniario que tengan un nexo causal con los hechos del caso concreto", que normalmente la Corte ordena repararlas fijando una compensación en equidad (Castillo Pérez vs. Perú, 27 de noviembre de 1998). Tercer elemento que, como se verá, en últimas resulta integrar y complementar, tanto al daño emergente, en unos casos, como al lucro cesante, en otros, por lo que se abordará en específico cada uno de estos factores. A los elementos del daño inmaterial se hará referencia con posterioridad.

Valga advertir, la indemnización, como medida de reparación del daño material y moral, solamente "[...] tiene carácter compensatorio y, por lo tanto, debe ser otorgada en la extensión y en la medida suficientes para resarcir los daños materiales y morales sufridos” (Garrido y Baigorria vs. Argentina, 27 de agosto de 1998, p. 47), puesto que, "[1]as reparaciones, como el término lo indica, consisten en las medidas que tienden a hacer desaparecer los efectos de las violaciones cometidas. Su naturaleza y su monto dependen del daño ocasionado en los planos tanto material como inmaterial. Las reparaciones no pueden implicar ni enriquecimiento ni empobrecimiento para la víctima o sus sucesores" (Servellón García y Otros vs. Honduras, 21 de septiembre de 2006, p. 163).

\section{b. El daño emergente}

El daño emergente engloba todos los gastos en que hayan tenido que incurrir las víctimas por causa de la violación a sus derechos.

[...] la Corte ha establecido que este (el daño emergente) debe englobar gastos que incurrieron las víctimas o 
sus familiares con el fin de dar con la verdad. La Corte es de criterio que dentro de estos gastos se incluyen visitas a instituciones, gastos por concepto de transporte, hospedaje, y por la búsqueda de la víctima. En caso de que se esté ante un caso de ejecución extrajudicial o desaparición forzada de personas, se podrán incluir ingresos dejados de percibir por alguno de los familiares durante la búsqueda a nivel interno o por asistir a las audiencias ante sede internacional. Igualmente, se incluyen gastos por tratamientos médicos recibidos por la víctima o por sus familiares por los diversos padecimientos en su salud como resultado de los hechos del caso, gastos por el desplazamiento de familiares a otras comunidades como consecuencia del hostigamiento que sufrieron por los hechos del caso, y gastos por sepultura. Es decir, la Corte ha establecido que debe existir un nexo causal entre los daños y los gastos (Rojas, s.f., p. 108). (Negrita y subrayas fuera del texto original).

Nótese que el daño emergente, como lo considera la Corte IDH, no se refiere únicamente a los gastos en que incurren las víctimas al momento de los hechos de la violación, por ejemplo, la sepultura o el transporte por causa de un desplazamiento forzado intempestivo, sino que también engloba las consecuencias de carácter pecuniario que tengan un nexo causal con los hechos del caso concreto. Ello es palmario en el caso "Radilla Pacheco vs. México" (23 de noviembre de 2009), cuando el Estado mexicano fue condenado por la Corte IDH a pagar por daño emergente la cantidad de 1.300 dólares de los Estados Unidos de América, en equidad, considerando, no el hecho mismo de la desaparición forzada del señor Rosendo Padilla Pacheco, sino el nexo causal que dicha violación tuvo en el detrimento patrimonial que sufrieron sus familiares al tener que hacer erogaciones económicas para desplazarse por el país, en procura de dar con el paradero del prenombrado.

Nash (2015, pp. 7-12), del análisis y sistematización de la jurisprudencia de la Corte IDH, resalta cuatro elementos que actualmente complementan el daño emergente en dicho Tribunal, más allá de la concepción tradicional de dicho concepto: 1. La exigencia de un perjuicio cierto, esto es, demostrar el vínculo entre el daño que se reclama y 
la violación sufrida (Ricardo Canesse vs. Paraguay, 31 de agosto de 2004, pp. 202-203), lo cual se flexibiliza cuando pasan muchos años para que el caso llegue al conocimiento de la Corte; 2 . La fijación en equidad de los gastos, cuando no hay prueba de ellos pero se presume su efectividad, en razón de la flexibilización de la prueba del perjuicio cierto (Anzualdo Castro vs. Perú, 22 de septiembre de 2009, p. 210); 3. La ampliación de la idea de compensación directa, estableciendo un monto mínimo de indemnización como medida adecuada de protección para las víctimas, cuando se ordena que los Estados sean quienes resuelvan ese asunto en la instancia nacional, pese a haber declarado la responsabilidad internacional del mismo (Chaparro Álvarez y Lapo Íñiguez vs. Ecuador, 21 de noviembre de 2007, pp. 228-232); 4. La concepción de nuevos sujetos que se deben indemnizar: la familia, a quien se debe compensar el "daño al patrimonio familiar" (Gutiérrez Soler vs. Colombia, 12 de septiembre de 2005, p. 78; Baldeón García vs. Perú, 06 de abril de 2006, p. 186), y las comunidades indígenas, como titulares de derechos colectivos, a quienes se les debe resarcir el "daño al patrimonio indígena común”, por el carácter colectivo de los derechos y, por consiguiente, de los daños y perjuicios sufridos (Comunidad Mayagna (Sumo) Awas Tingni vs. Nicaragua, 31 de agosto de 2001, p. 149; Comunidad Moiwana vs. Suriname, 15 de junio de 2005, p. 201).

\section{c. El lucro cesante o pérdida de ingresos}

Conocido, también, como "daño material indirecto" (para diferenciarlo del directo o daño emergente), el lucro cesante o pérdida de ingresos se refiere a "[...] las pérdidas patrimoniales ocasionadas por una merma de ingresos, con ocasión de una violación de derechos humanos" (Nash, 2009, p. 47).

La Corte IDH exige la existencia de un nexo entre la violación sufrida y el daño indirecto reclamado, mutatis 
mutandi, como ocurre en el caso del daño emergente. "En caso de que dicho nexo no exista, la Corte rechaza la solicitud" (Nash, 2009, p. 49).

El profesor dominicano Julio José Rojas Báez expone claramente lo que entiende la Corte IDH como daños materiales indirectos:

En cuanto al lucro cesante la Corte ha mantenido que la compensación debe ser acordada por el daño sufrido por la víctima o sus familiares por el tiempo en el que se han visto impedidos de trabajar debido a la violación. Sobre este particular, la Corte ha tomado como puntos de referencia para determinar el monto, la expectativa de vida en el país al momento de los hechos, las circunstancias del caso, el salario mínimo legal, y la pérdida de una chance cierta.

El lucro cesante se refiere mayormente a la interrupción de ingresos, salarios, honorarios, y retribuciones. En este sentido, refleja el perjuicio sobre condiciones concretas de las que realmente disfrutaba la víctima, así como la probabilidad de que tales condiciones continuasen y progresasen si la violación no hubiera tenido lugar. El lucro cesante tiene referente automático en el nivel de educación de la víctima, sus calificaciones profesionales, salarios y beneficios laborales. En un criterio bastante favorable para las víctimas y sus familiares, la Corte considera que un "adulto que percibe [...] ingresos y tiene familia, destina [...] la mayor parte de dichos ingresos a atender las necesidades... de ésta (Rojas, s.f., pp. 107-108).

La Corte IDH, en su primer caso contencioso, "Velásquez Rodríguez vs. Honduras” (21 de julio de 1989, p. 46), estableció que la indemnización compensatoria por lucro cesante debía calcularse según los ingresos que la víctima habría recibido hasta su posible muerte natural, lo cual debe tener en consideración

[...] las expectativas de vida para las personas habitantes del país, las expectativas de vida laboral del Estado donde se cometió la violación y los posibles ingresos que la víctima, en razón de su vida laboral y las actividades económicas que desarrollaba, dejó de percibir, a consecuencia de la violación, que la Corte ha sido consistente en fijar sobre la base de ingresos mínimos que prevé la legislación interna de cada 
país, bien como salario mínimo general, o en razón de las labores concretas a que se dedicaba la víctima cuando no es posible determinar cuánto realmente percibía como ingreso económico (Nash, 2009, p. 47).

Con todo, la Corte IDH distingue dos situaciones: cuando “[...] la indemnización corresponde a la víctima afectada, por incapacidad total o absoluta, o bien, si dicha indemnización le corresponde a los familiares directos de dicha persona, fijando en este segundo caso un criterio de mayor flexibilidad a la hora de ponderar la indemnización” (Nash, 2009, p. 47). Ponderación y cálculo que, mayoritariamente en la segunda de las situaciones, fija con base en el criterio de la equidad.

De igual modo, la Corte se ha preocupado de varias situaciones particulares y así, por ejemplo, ha fijado los dineros que la persona dejó de percibir en razón del ilícito como víctima directa; ha determinado la indemnización sobre la base de la acreditación que se haga en el proceso; ha determinado las consecuencias económicas y laborales de la separación ilegal de funciones; se ha fijado en las consecuencias económicas para los negocios de la víctima de una violación convencional imputable a la acción del Estado e, incluso, ha presumido que la víctima habría completado sus estudios, aun reconociendo que no puede determinar cuáles; o bien ha presumido la incorporación de las víctimas al mercado laboral activo al concluir sus estudios, entre otras cuestiones (Nash, 2009, p. 48). (Negrita y subrayas fuera del texto original).

De las líneas resaltadas en el párrafo anterior, Nash (2009) evidencia, sin decirlo, apoyado en los casos "El Amparo vs. Venezuela”, "Loayza Tamayo vs. Perú”, “Suárez Rosero vs. Ecuador”, “Castillo Páez vs. Perú”, "Baena Ricardo y Otros vs. Panamá”, "Cantoral Benavides vs. Perú”, “Tribunal Constitucional vs. Perú”, "Chaparro Álvarez y Lapo Íñiguez vs. Ecuador” e "Ivcher Bronstein vs. Perú”, que dichas consecuencias consideradas como lucro cesante son también secuelas de carácter pecuniario con nexo causal establecido en los hechos del caso 
concreto (el tercer elemento que tiene en cuenta la Corte IDH al momento de fijar una indemnización como reparación por daño material). Por ejemplo, en el caso "Fernández Ortega y Otros vs. México", la Corte IDH ordenó a los Estados Unidos Mexicanos compensar a la señora Inés Fernández Ortega y al señor Fortunato Prisciliano Sierra, con base en el criterio de equidad, en la suma de 5.000 dólares de los Estados Unidos de América, por la pérdida de ingresos de los prenombrados al haber tenido que descuidar sus tareas en la cosecha de su parcela a causa de la violación sexual a que fue sometida la señora Inés Fernández Ortega, por miembros del Ejército Nacional, pues ello le causó estigmatización y discriminación entre los mismos miembros de su comunidad indígena, haciendo que ella se refugiara en su domicilio, saliendo únicamente para asistir a las diligencias que buscaban promover la justicia en su caso, sin volver a ocuparse de la actividad económica que venía desarrollando normalmente hasta cuando los militares irrumpieron en su domicilio y abusaron sexualmente de ella (Fernández Ortega y Otros vs. México, 30 de agosto de 2010, pp. 283-286).

El profesor Nash (2009), además de tener en cuenta los elementos del lucro cesante que han sido desarrollados por la doctrina iusprivatista en materia de responsabilidad, enuncia que la Corte IDH tiene en cuenta la equidad al momento de calcular el monto de dicha compensación cuando no es posible determinar la misma con las pruebas obrantes en el proceso, pero que se pueda deducir, presumir y establecer razonablemente, además que tengan nexo con la violación sufrida (Instituto de Reeducación del Menor vs. Paraguay, 02 de septiembre de 2004, p. 288; Palamara Iribarne vs. Chile, 22 de noviembre de 2005, p. 242). Ello por cuanto, en tratándose de derechos humanos, no puede primar el criterio iusprivatista del análisis de responsabilidad desde el sujeto dañador, sino éste debe ser complementado desde la perspectiva de las víctimas, máxime en punto a las reparaciones, ya que ello supone determinar cómo 
se puede restituir a aquel que ha sido afectado en sus derechos fundamentales, cómo se puede restablecer su situación, no sólo patrimonialmente, sino integralmente (Nash, 2009, p. 36), donde se debe considerar a la persona, parafraseando a Ortega y Gasset en su obra Meditaciones del Quijote, con todas sus circunstancias.

En razón de la integralidad de la persona humana, considerando que existen sujetos de protección especial y en circunstancias de mayor vulnerabilidad, la Corte IDH ha vislumbrado que las violaciones de derechos humanos pueden significar y causar una pérdida importante de ingresos que han sido reconocidos como lucro cesante (Nash, 2015, p. 16):

[...] la Corte también se ha pronunciado respecto de titulares especiales de derechos, específicamente pueblos indígenas. Al respecto la Corte presume que los hechos que ocasionaron una violación a los derechos humanos de las comunidades, provocaron una "serie de ingresos dejados de percibir", al respecto:

"El Tribunal hace notar que no han sido aportados elementos probatorios suficientes y específicos para determinar el ingreso dejado de percibir por miembros del Pueblo Sarayaku la paralización de sus actividades en algunos períodos, así como por la siembra y venta de los productos que dejaron de realizarse en las chacras, por los alegados gastos para complementar su dieta ante la falta de alimentos en algunos períodos o por las afectaciones al turismo comunitario. [...] Sin embargo, en las circunstancias del presente caso, es razonable presumir que los hechos provocaron una serie de gastos e ingresos dejados de percibir, que debieron ser enfrentados por los miembros del Pueblo Sarayaku, el cual vio afectadas sus posibilidades de uso y goce de los recursos de su territorio, particularmente por la restricción de áreas de caza, de pesca y de subsistencia en general. Además, por la propia ubicación y modo de vida del Pueblo Sarayaku, es comprensible la dificultad para demostrar esas pérdidas y daños materiales”. La Corte, es consciente de la dificultad que significa para el pueblo indígena aportar elementos probatorios específicos, 
por lo que presume la pérdida de ingresos, estableciendo su indemnización en equidad (Pueblo Indígena Kichwa de Sarayaku vs. Ecuador, 27 de junio de 2012, p. 315).

\section{ii. Las reparaciones inmateriales}

\section{a. El daño inmaterial}

Es en este aspecto donde la Corte IDH ha evolucionado con paso más firme determinando los rubros que se deben indemnizar, al punto que, hoy por hoy, en su jurisprudencia ha reconocido la posibilidad de reparar a un colectivo, por concepto de daño inmaterial, siendo preciso distinguir entre las reparaciones individuales y reparaciones colectivas:

Las reparaciones individuales corresponden a aquellas otorgadas a titulares de derechos individuales, es decir, estas pueden corresponder tanto a una persona, como a un grupo de personas, siempre que éstas sean titulares de derechos individuales. Por otro lado, las reparaciones colectivas, corresponden a aquellas entregadas a un colectivo, es decir, a aquellas entregadas a un colectivo, es decir, a aquellos que son titulares de derechos colectivos, por ejemplo, pueblos indígenas. Por tanto, el criterio de distinción entre reparaciones individuales y colectivas no dice relación con el número de personas que perciben la indemnización, sino más bien con el tipo de derechos de que son titulares (Nash, 2015, p. 17).

Según la Corte IDH, el daño moral o inmaterial "puede comprender tanto los sufrimientos y las aflicciones causados a las víctimas directas y a sus allegados, y el menoscabo de valores muy significativos para las personas, como las alteraciones, de carácter no pecuniario, en las condiciones de existencia de la víctima o su familia" (Acosta Calderón vs. Ecuador, 24 de junio de 2005, p. 158), asociando "el daño moral con el padecimiento de miedo, sufrimiento, ansiedad, humillación, degradación, y la inculcación de sentimientos de inferioridad, inseguridad, frustración, e impotencia" (Rojas, s.f., p. 109).

Y así, en el entendido que no le es posible al hombre medir, cuantificar, tasar con un patrón de medida, 
cuánto vale su dolor, pues “[...] sólo puede ser objeto de compensación, en dos formas. En primer lugar, mediante el pago de una cantidad de dinero o la entrega de bienes o servicios apreciables en dinero, que el Tribunal determine en aplicación razonable del arbitrio judicial y en términos de equidad. Y, en segundo lugar, mediante la realización de actos u obras de alcance o repercusión públicos" (Acosta Calderón vs. Ecuador, 24 de junio de 2005, p. 158) aspecto de gran consideración para la Corte IDH, puesto que, como se anunció supra, ha avanzado en su jurisprudencia "desde considerar los criterios tradicionales del derecho privado para indemnizar el daño moral (pretium doloris), hacia integrar otros elementos al análisis, como las afectaciones a las condiciones de vida, los daños a la autoestima, el sentimiento de impunidad y las características especiales de ciertos titulares de derechos” (Nash, 2015, p. 23).

Se han integrado al análisis del daño moral aspectos muy concretos, diferentes al dolor, a saber (Nash, 2015, pp. 18-23): 1. El menoscabo de valores muy significativos para las personas y otras perturbaciones no susceptibles de medición pecuniaria, como por ejemplo, cuando las violaciones provocan que se tenga que ir en contra de las creencias y costumbres propias de las cosmovisión de una comunidad indígena (caso "Comunidad Moiwana vs. Suriname”, 15 de junio de 2005, p. 195), incorporándose así en el daño moral elementos culturales (Bámaca Velásquez vs. Guatemala, 22 de febrero de 2002, p. 56); 2. La afectación de relaciones sociales y familiares, verbi gratia, el caso de Karen Atala, quien por su orientación sexual debió sufrir, ella y sus hijas, diversos niveles de estigmatización y desasosiego (“Atala Riffo y Niñas vs. Chile”, 24 de febrero de 2012, p. 298); 3. Los sentimientos de discriminación, frustración, exclusión, impotencia e indefensión y demás aspectos subjetivos de apreciación personal que pudieran haber experimentado las víctimas, como la afectación a la autoestima (Yatama vs. Nicaragua, 
23 de junio de 2005, p. 246-247; Gutiérrez Soler vs.

Colombia, 12 de septiembre de 2005, p. 88; Palamara Iribarne vs. Chile, 22 de noviembre de 2005, p. 247; De la Cruz Flores vs. Perú, 18 de noviembre de 2004, p. 160; Hermanas Serrano Cruz vs. El Salvador, 01 de marzo de 2005, p. 160); 4. Las aflicciones y sufrimientos de las víctimas por la falta de investigación seria o por la inactividad del Estado, generando consecuentemente la sensación de impunidad (González y Otras (Campo Algodonero) vs. México, 16 de noviembre de 2009, p. 583); 5. Las características propias del titular del derecho, por ejemplo, cuando el afectado sufrió una mayor aflicción por su condición propia de vulnerabilidad, caso del señor Damião Ximenes Lopes quien padecía discapacidad mental y, no obstante su situación, fue sometido a tratos crueles e inhumanos mientras estuvo hospitalizado, lo que finalmente desencadenó su muerte (Ximenes Lopes vs. Brasil, 04 de julio de 2006, p. 237), o caso de María Claudia García Iruretagoyena de Gelman, pues ella, estando en embarazo (Gelman vs. Uruguay, Sentencia de 24 de febrero de 2011, p. 296), fue afectada en sus derechos fundamentales al ser detenida ilegalmente en Buenos Aires (Argentina), obligada a dar a luz a su hija en Uruguay, la cual le fue arrebatada, para finalmente ser desaparecida, o también en el caso de los niños, como ocurrió con Marco Antonio Molina Theissen, quien siendo un infante, sujeto de especial protección (Molina Theissen vs. Guatemala, 03 de julio de 2004, p. 67), fue detenido y secuestrado por agentes del Estado y luego hecho desaparecer, asimismo en el caso de las comunidades indígenas como titulares especiales de derechos colectivos.

No sobra recordar que, si bien la Corte IDH omite la necesidad de la prueba para estimar que hubo daño moral a causa de la violación a los derechos humanos, Nash (2015, p. 18) advierte que "en situaciones particulares, podría acreditarse un daño mayor al "evidente" por medios de prueba particulares, por ejemplo, mediante peritajes médicos, testigos, u otros”, en tanto, según la jurisprudencia del 
Tribunal, la sentencia per se constituye una forma de reparación del daño inmaterial, pero se puede estar ante situaciones de graves violaciones de derechos humanos que por el grado de las afectaciones y daños irrogados, puede resultar procedente un pago de compensación por daño moral, conforme a la equidad (La Cantuta vs. Perú, 24 de junio de 2005, p. 219).

\section{b. La indemnización por daño moral a un colectivo}

El autor seguido concluye, con total acierto, según la jurisprudencia de la Corte IDH, "que es procedente reparar los daños inmateriales sufridos por las comunidades, por actuaciones u omisiones del Estado, que violen las obligaciones internacionales" (Nash, 2015, p. 24), donde el sujeto de la indemnización puede ser un sujeto colectivo, como en el caso del Pueblo Sarayaku, entregando directamente las indemnizaciones a las comunidades indígenas, en superación del paternalismo que en otrora había tenido la Corte, "para que ellas mismas elijan su destino [...], ya que reconoce plenamente a los pueblos indígenas como sujetos de derechos y respeta sus propias formas de organización, dando concreción al principio de igualdad y no discriminación” (Nash, 2015, p. 25).

\section{c. El proyecto de vida}

En el texto publicado en 2009, Las reparaciones ante la Corte Interamericana de Derechos Humanos (1988-2007), el autor austral Nash consideró que la alusión al proyecto de vida, que hizo en un primer momento la Corte IDH en el caso "Loayza Tamayo vs. Perú", y que posteriormente retomó en el caso "Gutiérrez Soler vs. Colombia”, en concreto estaba vinculado con el daño inmaterial, como se vio supra, pues para resarcir el "proyecto de vida”, la Corte ordenó medidas de reparación de carácter médico y psicológico (Nash, 2009, p. 58). 
En efecto, la Corte nos señala que la finalidad de utilizar esta figura es: "ayudar en la construcción de un nuevo proyecto de vida para la familia"; sin embargo, no da luces de si este criterio es utilizado como medida de satisfacción, como medio para cuantificar el daño moral o si simplemente forma parte de una categoría distinta. Nos parece que si bien el proyecto de vida puede constituir un aspecto interesante a abordar en materia de reparaciones, es necesario esclarecer cuál es su área de influencia, a efectos de legitimar normativamente y en la práctica su utilización por la Corte al momento de realizar el análisis” (Nash, 2015, pp. 30-31).

El desconcierto del profesor Nash se suscitó desde la sentencia del año 2009 "Campo Algodonero vs. México”, cuando la Corte IDH desarrolló los límites en relación con el proyecto de vida sosteniendo "[...] que la reparación por dicho concepto no procede cuando la víctima ha fallecido, al ser imposible reponer las expectativas de realización que razonablemente toda persona tiene” (González y Otros (Campo Algodonero) vs. México, 16 de noviembre de 2009, p. 589), acrecentándose con los casos "Atala Riffo y Niñas vs. Chile” y “Artavia Murillo y Otros vs. Costa Rica”, ambos de 2012, donde refiere la Corte IDH que, tanto la forma como se ejerce la orientación sexual, en el primero, como el derecho a ejercer la fecundación in vitro, en el segundo, son despliegues del proyecto de vida de las víctimas.

Entonces, haciendo un ejercicio de esclarecimiento de lo que podría ser la categoría "proyecto de vida” en materia de reparaciones, en congruencia con lo dispuesto en la sentencia "Campo Algodonero vs. México”, no podría decirse que es un elemento del daño moral, ya que, como las víctimas directas murieron, lo que establece el Tribunal es que no procede reparación alguna por daño al proyecto de vida de quien ya no existe $y$, por ende, no tiene una vida que proyectar y realizar, contrario sensu, si el daño al proyecto de vida fuera un elemento del daño moral, sería totalmente indemnizable, pues el mismo sería transmisible por causa de muerte”. El derecho a la indemnización por los daños 
sufridos por la víctima hasta el momento de su muerte se transmite por sucesión a sus herederos, y los daños provocados por la muerte de la víctima a sus familiares o a terceros pueden ser reclamados por éstos fundándose en un derecho propio" (Trujillo Oroza vs. Bolivia, 27 de febrero de 2002, p. 86).

El proyecto de vida podría ser entendido, con mayor sentido, como un elemento a tener en cuenta para implementar medidas de satisfacción y/o de rehabilitación, pues siguiendo la lógica de la Corte IDH, éste es importante cuando las víctimas continúan con vida y la afectación a sus derechos se dio en el despliegue y ejercicio, o en la restricción de derechos, que no acabo por fortuna con su existencia, pero que si impidió, de alguna manera, el desarrollo del propio proyecto de vida.

\section{iii. Otras formas de reparación}

Hasta ahora se tiene un panorama de las formas de reparación clásicas del derecho privado, esto es, el daño emergente, el lucro cesante y el daño moral, con la riqueza y desarrollo que les ha infundido la jurisprudencia de la Corte IDH.

Con todo, esas modalidades de carácter indemnizatorio no son las únicas que considera la Corte IDH para reparar integralmente a las víctimas. Así las cosas, dicho Tribunal ha ido estableciendo formas de reparación no materiales denominadas restitución, rehabilitación, satisfacción y garantías de no repetición. "Estas medidas poseen un enorme poder de reparación en situaciones de violación de los derechos humanos. La posición de la víctima de violaciones de derechos fundamentales no tiene sólo una óptica material y dicho aspecto no es el más importante. Los aspectos más relevantes dicen relación con la verdad, el restablecimiento del honor, la justicia, los cambios internos en el Estado, entre otros" (Nash, 2009, p. 59). 


\section{a. Restitución}

Ya se hizo referencia a este aspecto supra. No obstante, se reitera que siempre que sea posible se debe propender por devolver a la víctima a la situación previa a la violación de sus derechos, como lo ha hecho la Corte IDH cuando ha ordenado anular procesos por privación del derecho al debido proceso, eliminar antecedentes penales o la liberación en casos de privación de la libertad, entre otros (Nash, 2009, p. 60).

\section{b. Medidas de rehabilitación}

Las medidas de rehabilitación buscan que las víctimas de afectaciones en sus derechos reciban una atención integral que propenda por borrar los padecimientos psicológicos y morales sufridos, amén que se les proporcione también toda la asistencia legal y social necesaria para desarrollar su vida de manera normal, ejerciendo plenamente sus derechos.

Tratamiento que ha de ser prestado por personal especializado y que debe considerar las condiciones, circunstancias y necesidades particulares de cada una de las víctimas (Masacre de las dos erres vs. Guatemala, 24 de noviembre de 2009, pp. 269-270). Así pues, en unos casos, no sólo las medidas de rehabilitación harán referencia a tratamiento médico, sino que, por ejemplo, pueden ordenar la reintegración de los trabajadores a sus empleos (Baena Ricardo vs. Panamá, 02 de febrero de 2001, punto resolutivo No 7), en clara alusión a medidas de rehabilitación de tipo legal y social, concretamente en el campo laboral.

\section{c. Medidas de satisfacción}

Acosta López y Bravo Rubio se refieren a las medidas de satisfacción como:

[...] aquellas que buscan reparar el daño inmaterial, que no tienen alcance pecuniario, y deben tener alcance y repercusión pública. Estas medidas de determinan considerando la especial relevancia del caso y la gravedad de los hechos, por lo cual pueden variar de un caso a otro. Generalmente se 
fijan considerando los hechos probados, y las posiciones de la Comisión, los representantes de los familiares de las víctimas y del Estado involucrado en el caso ante la Corte IDH (Acosta y Bravo, 2008, pp. 332-333).

Sergio García Ramírez (2005, p. 80) acota que las medidas de satisfacción buscan compensar el detrimento de bienes no patrimoniales como el prestigio, el honor, la buena fama de las víctimas, es decir, aspectos que van más allá del fuero interno de la persona y lo pone en relación con su comunidad, a la vez que permiten su inmersión y participación con dignidad en la sociedad.

Nash (2009, pp. 62-63) enlista las medidas de satisfacción que la Corte IDH ha desarrollado: "ofrecimiento de disculpas públicas a las víctimas; difusión de la petición de perdón a través de Internet; memoriales y actos conmemorativos; establecimiento de días nacionales; cambio de nombre de calles, plazas, centros médicos o escuelas para conmemorar a las víctimas; publicación de la sentencia de la Corte IDH en un diario de circulación nacional del país donde se cometió la violación publicación de la sentencia -traducida al idioma oficial correspondiente- en el territorio del país donde vive la víctima; transmisión radial de ciertos párrafos de la sentencia en una radio de fácil acceso a las víctimas involucradas en el caso; publicación de la sentencia y difusión radial y televisada de partes de la sentencia; publicación especial -dentro del territorio nacional- en la cual se señalen las violaciones sufridas por las víctimas y su inocencia en los hechos imputados; traducción de ciertos párrafos a los idiomas de las víctimas" y la entrega de restos mortales de detenidos-desaparecidos, verbi gratia, como ocurrió en el caso "Bámaca Velásquez vs. Guatemala", donde resultó sumamente importante para sus deudos dar sepultura, según sus creencias religiosas y costumbres culturales, al señor Efraín Bámaca, pues sólo así, y únicamente así, estarían satisfechos en sus derechos ya que asegurarían la 
posibilidad de un reencuentro entre vivos, el fallecido y los antepasados del pueblo maya.

\section{d. Garantías de no repetición}

Son aquellas acciones que debe desplegar el Estado en procura de que la situación que generó la violación de derechos humanos no se vuelva a presentar. Tienen una finalidad preventiva pero a la vez reparadora para las víctimas que hayan sufrido merma en sus derechos. Rojas se refiere a ellas como "[...] garantías por excelencia, ya que tienen por finalidad corregir la falla que genera el ilícito a nivel interno. En su jurisprudencia constante, la Corte ha ordenado medidas que pueden clasificarse en tres renglones: acción y revisión legislativa, investigación y acción judicial, y acción ejecutiva" (Rojas, s.f., p. 120).

Como garantía de no repetición, en el ámbito legislativo, está el caso "La Última Tentación de Cristo vs. Chile", donde la Corte IDH ordenó adecuar la legislación interna de Chile, nada más ni nada menos que su propia Constitución, porque la misma, en su artículo 19, numeral 12, que preveía la censura previa, no resultaba acorde con la Convención Americana de Derechos Humanos (La Última Tentación de Cristo (Olmedo Bustos y Otros) vs. Chile, 05 de febrero de 2001, p. 97).

En el ámbito judicial, en el caso "Fermín Ramírez vs. Guatemala”, la Corte IDH llamó la atención para que, en lo sucesivo, el Estado adopte las medidas necesarias para garantizar "la no repetición" de procedimientos irregulares que puedan producir efectos irreparables, como le ocurrió al señor Fermín Ramírez al verse compelido a un proceso penal sin garantía de sus derechos fundamentales a la defensa y a la audiencia (Fermín Ramírez vs. Guatemala, 20 de junio de 2005, p. 125 n.).

Respecto al ejecutivo, en el caso "Hermanas Serrano Cruz vs. El Salvador” (01 de marzo de 2005, pp. 189-193), la Corte IDH ordenó la creación de una página Web de búsqueda de desaparecidos y de un sistema de información genética, en 
razón de la gran cantidad de personas que desaparecieron durante el conflicto civil salvadoreño.

Nash (2009, pp. 63-64) señala, en general, las garantías de no repetición que ha ido estableciendo la Corte IDH en su jurisprudencia así:

[...] la exigencia de adecuación de la legislación interna; derogación de normas vigentes contrarias a la Convención; formación de los funcionarios públicos en derechos humanos; información sobre los resultados de los procesos de formación comprometidos por los Estados; señalamiento de ciertos mínimos en la capacitación que deben recibir funcionarios públicos en materia de derechos humanos; mejoramiento de las condiciones carcelarias; garantía del derecho de acceso a información bajo control del Estado; campaña nacional de sensibilización sobre la situación de los niños; medidas para dotar de eficacia al recurso de "habeas corpus", respecto de los casos de desaparición forzada; promoción de mecanismos de prevención, vigilancia y solución de conflictos sociales, entre otras.

El mismo Nash (2015, p. 10) pone de presente un aspecto de la jurisprudencia reciente de la Corte IDH en materia de garantías de no repetición: que la finalidad de dichas medidas deben incluir un carácter transformador, sobre todo en tratándose de erradicar bases estructurales que permitan o faciliten violaciones de derechos humanos.

La Corte resalta que algunos actos discriminatorios analizados en capítulos previos se relacionaron con la reproducción de estereotipos que están asociados a la discriminación estructural e histórica que han sufrido las minorías sexuales (supra párr. 92), particularmente en cuestiones relacionadas con el acceso a la justicia y la aplicación del derecho interno. Por ello, algunas de las reparaciones deben tener una vocación transformadora de dicha situación, de tal forma que las mismas tengan un efecto no sólo restitutivo sino también correctivo hacia cambios estructurales que desarticulen aquellos estereotipos y prácticas que perpetúan la discriminación contra la población LGTBI (Atala Riffo y Niñas vs. Chile, 24 de febrero de 2012, p. 267). 
También las garantías de no repetición deben propender por "mejorar las condiciones de vida de las víctimas que viven en situaciones graves de discriminación y exclusión social. En estos casos, la Corte no se limita a disponer medidas genéricas vinculadas al tipo de derecho afectado (condiciones de vida), sino que dispone en detalle lo que el Estado debe hacer para garantizar ciertos mínimos” (Nash, 2015, p. 12).

En los casos "Masacre Plan de Sánchez vs. Guatemala" (19 de noviembre de 2004, p. 110) y "Comunidad Indígena Yakye Axa vs. Paraguay” (17 de junio de 2005, p. 221), la Corte IDH ordenó la implementación y el desarrollo de programas concretos de contenido prestacional, en pro de la superación y transformación de las condiciones que permitieron que dichas comunidades vieran vulnerados sus derechos humanos, de manera recurrente, como si fuera "lo normal” (Nash, 2015, pp. 12-13).

\section{e. Las actuaciones en el ámbito interno: investigación, juzgamiento y sanción}

Pablo Saavedra Alessandri refiere que los Estados tienen el deber de investigar, seria y efectivamente, los hechos objeto de la violación, identificar a todos los responsables y sancionarlos, lo cual, en su entender, resalta la importancia que da la Corte al combate contra la impunidad como medida de reparación para las víctimas, pero también como forma de prevención, es decir, "para que no se repita”, pues si un Estado no despliega las acciones conducentes a que los responsables de hechos violatorios a los derechos humanos reciban una sanción por sus crímenes, pues se tendrá un ambiente propicio para que se vuelvan a repetir esas trasgresiones, incluso con mayor sevicia y barbarie, amén de la persistencia del sentimiento de vulnerabilidad e inseguridad de las personas frente al mismo Estado y la sociedad.

El deber de investigar está estrecha e íntimamente relacionado con el derecho a la verdad que tienen las víctimas y la sociedad, en satisfacción del derecho a la verdad histórica 
(Nash, 2015). En ese sentido se ha pronunciado la Corte IDH:

El Tribunal estima que el derecho a conocer la verdad tiene como efecto necesario que en una sociedad democrática se conozca la verdad sobre los hechos de graves violaciones de derechos humanos. Esta es una justa expectativa que el Estado debe satisfacer, por un lado, mediante la obligación de investigar las violaciones de derechos humanos y, por el otro, con la divulgación pública de los resultados de los procesos penales e investigativos. Resulta esencial para garantizar el derecho a la información y a conocer la verdad que los poderes públicos actúen de buena fe y realicen diligentemente las acciones necesarias para asegurar la efectividad de ese derecho, especialmente cuando se trata de conocer la verdad de lo ocurrido en casos de violaciones graves de derechos humanos como las desapariciones forzadas del presente (Contreras y Otros vs. El Salvador, 31 de agosto de 2011, p. 170).

En casos de graves violaciones a los derechos humanos, las obligaciones positivas inherentes al derecho a la verdad exigen la adopción de los diseños institucionales que permitan que este derecho se realice en la forma más idónea, participativa y completa posible y no enfrente obstáculos legales o prácticos que lo hagan ilusorio. La Corte resalta que la satisfacción de la dimensión colectiva del derecho a la verdad exige la determinación procesal de la más completa verdad histórica posible, lo cual incluye la determinación judicial de los patrones de actuación conjunta y de todas las personas que de diversas formas participaron en dichas violaciones y sus correspondientes responsabilidades. Dicha investigación debe ser asumida por el Estado como un deber jurídico propio y no como una simple gestión de intereses particulares, que dependa de la iniciativa procesal de las víctimas o de sus familiares o de la aportación privada de elementos probatorios. En cuanto a la participación de las víctimas, se debe garantizar que, en todas las etapas de los respectivos procesos, las víctimas puedan formular sus pretensiones y presentar elementos probatorios y que éstos sean analizados de forma completa y seria por las autoridades antes de que se resuelva sobre hechos, responsabilidades, penas y reparaciones (Masacre de La Rochela vs. Colombia, 11 de mayo de 2007, p. 195). 
Núñez y Zuluaga (2012, pp. 217-219) enfatizan en que el derecho a la verdad es instrumento esencial para combatir la impunidad en casos de violaciones de derechos humanos, el cual, según la interpretación de la Corte IDH, es un derecho en construcción al que se reconoce únicamente una dimensión individual pero no colectiva, surgiendo el interrogante sobre si "la verdad" es una medida de satisfacción o una garantía de no repetición, o si sólo integra el aspecto de investigación, juzgamiento y sanción en el ámbito interno, pues la Corte IDH "[...] determinó que este derecho es un correlato necesario del derecho de garantías judiciales del artículo 8.1 de la CADH (caso Blake frente a Guatemala, 1998)" (Núñez \& Zuluaga, 2012, p. 218) y, en ese sentido, no tendría que ver "la verdad" con aspectos que pongan a las víctimas en relación con su comunidad, con ámbitos de relevancia social y pública.

Sin embargo, el derecho a la verdad, como forma de reparación, no es posible clasificarlo en uno u otro modo en que ésta se expresa ya que reviste características tanto de medida de satisfacción como de garantía de no repetición, como exponen Núñez y Zuluaga (2012):

[...] en el caso Bámaca Velásquez frente a Guatemala (2000), (la Corte IDH) confirmó el ámbito individual del derecho a la verdad y negó su dimensión colectiva. En el mismo sentido, se refirió al analizar las leyes de autoamnistía en el caso conocido como Barrios Altos. Si bien negó la dimensión colectiva de este derecho, fundó la obligación estatal de divulgar los resultados de la investigación y de los juicios que se debían adelantar por la carencia de efectos válidos de las leyes impugnadas (caso Barrios Altos contra Perú, 2001).

Esta sentencia es vital dentro del reconocimiento de la verdad como una forma de reparación al ordenar la reapertura de investigaciones, el ofrecimiento de disculpas públicas, y la publicación de la sentencia condenatoria en el diario oficial.

Desde ese momento, se consideró que el reconocimiento de la verdad era la forma primordial de reparación de las víctimas, y en sucesivas sentencias la Corte IDH la ha tomado como precedente obligatorio. Así, en una de sus más recientes sentencias, le ordenó al Estado ecuatoriano efectuar 
investigaciones administrativas que lograran establecer

la verdad respecto a la actuación de algunos funcionarios públicos (caso Mejía Idrovo frente a Ecuador, 2011) (Núñez \& Zuluaga, 2012, p. 219).

El deber de investigar y sancionar debe ser cumplido con toda seriedad por parte del Estado, con la participación de los representantes de las víctimas en todas las etapas de la investigación y el juzgamiento, con resultados públicos (Carpio Nicolle vs. Guatemala, 22 de noviembre de 2004, p. 129), en cumplimiento de la obligación de garantía, concretamente del artículo 8 y 25 de la Convención Americana de Derechos Humanos, aunado a la observancia del artículo 63.1 del mismo marbete, cuando ya ha sido declarado responsable el Estado.

En el caso "Carpio Nicolle vs. Guatemala” (22 de noviembre de 2004, p. 135) la Corte IDH llamó la atención en punto a que el Estado debía fortalecer sus capacidades investigativas, dotando a las entidades encargadas de investigar las ejecuciones extra judiciales, de recursos económicos, humanos, logísticos y científicos suficientes para cumplir adecuadamente con dicha labor, conforme con la normatividad internacional, así como en otros pronunciamientos ha puesto de presente el deber de atender las específicas circunstancias de los sujetos vulnerados en sus derechos (Rosendo Cantú y Otra vs. México, 31 de agosto de 2010, p. 178), pues ello impone a los Estados ofrecer los medios para que puedan participar de la investigación, sin que ello vaya a resultar en sí mismo una revictimización ${ }^{2}$, o impida acceder efectivamente a la verdad como medida de reparación.

Saavedra Alessandri aborda una cuestión interesante: si la Corte IDH ha ordenado, como medida de reparación no pecuniaria, que se investiguen y sancionen efectivamente a todos los responsables de las violaciones a los derechos humanos, pues ello implica que, en su país, la víctima tenga que seguir haciendo erogaciones económicas para

2. Revictimización o doble victimización: "Son repetidas situaciones por las que tienen que pasar las víctimas después de haber sido afectadas por algún delito [...], ante los organismos judiciales, viéndose obligadas a testificar un número infinito de veces, perjudicándose psicológica y emocionalmente de manera más profunda y traumática a la víctima [...]". En: Coronel, Gutiérrez de P. y Pérez, 2009, p. 51. 
atender el proceso judicial en el fuero interno. $\mathrm{Si}$, por lo general, la Corte ordena que los Estados paguen las costas y gastos originados por el proceso interno y ante el Sistema Interamericano, "¿no sería procedente también que se paguen los gastos y costas futuros en que la víctima o sus familiares van a incurrir en la búsqueda de justicia ordenada por la Corte? Sobre el particular, creo que se debería contemplar en las sentencias de la Corte una mención especial a los gastos y costas futuras dentro del capítulo correspondiente. En este sentido, cabe resaltar que la Corte ya hizo mención a gastos judiciales futuros en el caso del Caracazo, los cuales los cuantificó debidamente”.

\section{Conclusiones}

Son indudables los avances de la jurisprudencia de la Corte IDH respecto a medidas de reparación por violaciones de derechos humanos, ello en procura de una mayor eficacia del derecho a la reparación. Sin embargo, éste no es un asunto completamente acabado y, justamente por ello, es un tema de discusión constante. Por ejemplo, la indemnización en equidad y sus montos, o el concepto de afectación al proyecto de vida, ya sea como un elemento del daño moral o como ítem a indemnizar de manera totalmente independiente, son aspectos que deben ser desarrollados y concretados por ese Tribunal Internacional en procura de la certeza jurídica, primero de las víctimas, pero también de los jueces de los países pertenecientes al Sistema Interamericano de Derechos Humanos, que se entienden auténticos jueces de convencionalidad de dicho Sistema y que, las más de las veces, pueden hallarse en encrucijadas sobre cómo reparar a las víctimas de violaciones de derechos humanos, sobretodo en la jurisdicción contencioso administrativa. El horizonte y objetivo debe ser la concreción real y eficaz del derecho a la reparación para las víctimas de violaciones de derechos humanos en su situación particular, quienes, en muchas ocasiones resultan pertenecer a sectores de la población 
marginados, víctimas de situaciones estructurales de desprotección y vulneración de sus derechos.

Se exige de la Corte IDH mayor certeza respecto de lo que Beristain (2010, p. 173) denomina reparación "desde una perspectiva jurídica”, para que los jueces de día en día se empoderen como auténticos jueces de convencionalidad del Sistema Interamericano de Derechos Humanos, teniendo claras las categorías y criterios jurídicos, "las reglas de juego", sin que se olvide que subyacen a las violaciones de derechos humanos patrones sistemáticos de violencia y discriminación que no pueden ser obviados y que deben ser reparados con vocación "transformadora”; ello impide una estandarización absoluta de las medidas de reparación, pues la realidad muchas veces excede lo regulado por el Derecho, posibilitando casos concretos en que esa vocación "transformadora" de las reparaciones considere necesario que se apliquen criterios de justicia distributiva, que no sólo correctiva, que, en todo caso, requerirán el insoslayable sustento y certeza jurídica proveniente de la jurisprudencia de la Corte IDH. 


\section{Referencias bibliográficas}

Acosta, J. \& Bravo, D. (2008). El cumplimiento de los fines de reparación integral de las medidas ordenadas por la Corte Interamericana de Derechos Humanos: énfasis en la experiencia colombiana. Int. Law: Revista Colombiana de Derecho Internacional. Bogotá, D.C.: Pontificia Universidad Javeriana. Recuperado de: http://www.scielo.org.co/pdf/ilrdi/n13/n13a10.pdf.

Asamblea General de las Naciones Unidas. (2005). Principios y directrices básicos sobre el derecho de las víctimas de violaciones manifiestas de las normas internacionales de derechos humanos y de violaciones graves del derecho internacional humanitario a interponer recursos y obtener reparaciones. Resolución 60/147.

Beristain, C. (2010). Diálogos sobre la reparación. Qué reparar en los casos de violaciones de derechos humanos. San José de Costa Rica: Instituto Interamericano de Derechos Humanos. Recuperado de: https://www.iidh.ed.cr/IIDH /media/1585/dialogossobre-la-reparacion-2010.pdf.

Botero, C., \& Restrepo, E. (2006). Estándares internacionales y procesos de transición en Colombia. En R. Uprimny, M. Saffon, C. Botero \& E. Restrepo. ¿Justicia transicional sin transición? Verdad, justicia y reparación para Colombia. Bogotá, D.C.: Centro de Estudios de Derecho, Justicia y Sociedad.

Calderón, J. (s.f.). La reparación integral en la jurisprudencia de la Corte Interamericana de Derechos Humanos: estándares aplicables al nuevo paradigma mexicano. México: Instituto de Investigaciones Jurídicas de la Universidad Nacional Autónoma de México. Recuperado de: http://www. juridicas.unam.mx/publica/librev/rev/derhumex/cont/14/art/art2.pdf.

Convención Americana sobre Derechos Humanos. Recuperado de: http://www.oas.org/ dil/esp/tratados_B-32_Convencion_Americana_sobre_Derechos_Humanos.pdf

Coronel, E., Gutiérrez de Piñeres, C. \& Pérez, C. (2009). Revisión teórica del concepto de victimización secundaria. Bogotá, D.C.: Universidad Cooperativa de Colombia. Recuperado de: http://www.scielo.org.pe/pdf/liber/v15n1/a06v15n1.pdf.

Faúndez, H. (1999). El Sistema Interamericano de Protección de los Derechos Humanos. Aspectos institucionales y procesales. San José de Costa Rica: Instituto Interamericano de Derechos Humanos.

García, S. (2005). La jurisprudencia de la Corte Interamericana de Derechos Humanos en materia de reparaciones. En A. Abreu, A. Cançado, S. García, D. García-Sayán, O. Jackman, C. Medina, P. Saavedra \& M. Ventura, La Corte 
Interamericana de Derechos Humanos. Un cuarto de siglo: 1979-2004. Recuperado de: http://www.corteidh.or.cr/docs/libros/cuarto\%20de\%20siglo.pdf.

López, C. (2009, dic.). Aproximación a un estándar de reparación integral en procesos colectivos de violación a los derechos humanos. Jurisprudencia de la Corte Interamericana de Derechos Humanos. Revista Estudios Socio-Jurídicos, Universidad del Rosario 11(2): 301-334.

Nash, C. (2009). Las reparaciones ante la Corte Interamericana de Derechos Humanos (1988-2007). Santiago de Chile: Universidad de Chile.

Nash, C. (2015). Guía docente, curso virtual: Las modalidades de reparación en la Corte Interamericana de Derechos Humanos. Madrid: Universidad Carlos III de Madrid / Fundación Gregorio Peces-Barba. Recuperado de: http:// fundaciongregoriopeces-barba.org/modalidadesdereparacion/.

Núñez, R. \& Zuluaga, L. (2012). Estándares internacionales de reparación de violaciones de derechos humanos: principios de implementación en el derecho colombiano. Revista Análisis Internacional -RAI-, Universidad de Bogotá Jorge Tadeo Lozano, No 6. Recuperado de: http://revistas.utadeo.edu.co/index.php/ $\mathrm{RAI} /$ article/view/853/864.

Ortega y Gasset, J. (s.f.). Meditaciones del Quijote. Recuperado de: http://www. mercaba.org/SANLUIS/Filosofia/autores/Contempor\%C3\%A1nea/Ortega\%20 y\%20Gasset/Meditaciones\%20del\%20Quijote.pdf.

Rojas, J. (s.f.). La jurisprudencia de la Corte Interamericana de Derechos Humanos en materia de reparaciones y los criterios del proyecto de artículos sobre responsabilidad del Estado por hechos internacionalmente ilícitos. Washington, D.C.: American University / Washington College of Law. Recuperado de: https://www.wcl.american.edu/journal/ilr/23/baez.pdf.

Saavedra, P. (s.f.). Las reparaciones en el Sistema Interamericano de Derechos Humanos. Recuperado de: http://www.usergioarboleda.edu.co/instituto_derechos_ humanos/pablo_saavedra_alessandri.htm.

Uprimny, R. (2005). ¿Justicia Transicional sin transición? Verdad, justicia y reparación para Colombia. Bogotá, D.C.: Centro de Estudios de Derecho, Justicia y Sociedad. 


\section{Referencias jurisprudenciales}

Corte IDH. “Velásquez Rodríguez vs. Honduras”. Sentencia de 21 de julio de 1989.

Corte IDH. "Aloeboetoe y Otros vs. Surinam”. Sentencia de 10 de septiembre de 1993.

Corte IDH. "Garrido y Baigorria vs. Argentina”. Sentencia de 27 de agosto de 1998.

Corte IDH. “Castillo Páez vs. Perú”. Sentencia de 27 de noviembre de 1998.

Corte IDH. Loayza Tamayo vs. Perú, Sentencia de 27 de noviembre de 1998.

Corte IDH. “Blake vs. Guatemala”. Sentencia de 22 de enero de 1999.

Corte IDH. “Baena Ricardo vs. Panamá”. Sentencia de 02 de febrero de 2001.

Corte IDH. "La Última Tentación de Cristo (Olmedo Bustos y Otros vs. Chile)".

Sentencia de 05 de febrero de 2001.

Corte IDH. "Comunidad Mayagna (Sumo) Awas Tingni vs. Nicaragua”. Sentencia de 31 de agosto de 2001.

Corte IDH. "Bámaca Velásquez vs. Guatemala”. Sentencia de 22 de febrero de 2002.

Corte IDH. “Trujillo Oroza vs. Bolivia”. Sentencia de 27 de febrero de 2002.

Corte IDH. "Molina Theissen vs. Guatemala”. Sentencia de 03 de julio de 2004.

Corte IDH. "Ricardo Canesse vs. Paraguay”. Sentencia de 31 de agosto de 2004.

Corte IDH. "Instituto de Reeducación del Menor vs. Paraguay”. Sentencia de 02 de septiembre de 2004.

Corte IDH. “De la Cruz Flores, vs. Perú”. Sentencia de 18 de noviembre de 2004.

Corte IDH. “Masacre Plan de Sánchez vs. Guatemala”. Sentencia de 19 de noviembre de 2004.

Corte IDH. “Carpio Nicolle vs. Guatemala”. Sentencia de 22 de noviembre de 2004.

Corte IDH. "Hermanas Serrano Cruz vs. El Salvador". Sentencia de 01 de marzo de 2005.

Corte IDH. "Comunidad Moiwana vs. Suriname”. Sentencia de 15 de junio de 2005.

Corte IDH. "Comunidad Indígena Yakye Axa vs. Paraguay". Sentencia de 17 de junio de 2005.

Corte IDH. "Fermín Ramírez vs. Guatemala”. Sentencia de 20 de junio de 2005.

Corte IDH. "Yatama vs. Nicaragua”. Sentencia de 23 de junio de 2005. 
Corte IDH. “Acosta Calderón vs. Ecuador”. Sentencia de 24 de junio de 2005.

Corte IDH. "La Cantuta vs. Perú”. Sentencia de 24 de junio de 2005.

Corte IDH. “Gutiérrez Soler vs. Colombia”. Sentencia de 12 de septiembre de 2005.

Corte IDH. "Palamara Iribarne vs. Chile". Sentencia de 22 de noviembre de 2005.

Corte IDH. "Baldeón García vs. Perú”. Sentencia de 06 de abril de 2006.

Corte IDH. "Ximenes Lopes vs. Brasil”. Sentencia de 04 de julio de 2006.

Corte IDH. "Servellón García y Otros vs. Honduras”. Sentencia de 21 de septiembre de 2006.

Corte IDH. "Masacre de La Rochela vs. Colombia”. Sentencia de 11 de mayo de 2007.

Corte IDH. "Chaparro Álvarez y Lapo Íñiguez vs. Ecuador”. Sentencia de 21 de noviembre de 2007.

Corte IDH. “Anzualdo Castro vs. Perú”. Sentencia de 22 de septiembre de 2009.

Corte IDH. "González y Otras (Campo Algodonero) vs. México”. Sentencia de 16 de noviembre de 2009.

Corte IDH. "Radilla Pacheco vs. México". Sentencia de 23 de noviembre de 2009.

Corte IDH. "Masacre de las dos erres vs. Guatemala". Sentencia de 24 de noviembre de 2009.

Corte IDH. "Fernández Ortega y Otros vs. México”. Sentencia de 30 de agosto de 2010.

Corte IDH. "Rosendo Cantú y Otra vs. México”. Sentencia de 31 de agosto de 2010.

Corte IDH. “Gelman vs. Uruguay”. Sentencia de 24 de febrero de 2011.

Corte IDH. "Chocrón vs. Venezuela”. Sentencia de 01 de julio de 2011.

Corte IDH. “Contreras y Otros vs. El Salvador”. Sentencia de 31 de agosto de 2011.

Corte IDH. “Atala Riffo y Niñas vs. Chile”. Sentencia de 24 de febrero de 2012.

Corte IDH. "Pueblo Indígena Kichwa de Sarayaku vs. Ecuador". Sentencia de 27 de junio de 2012.

Corte IDH. "Artavia Murillo y Otros (Fecundación in Vitro) vs. Costa Rica”. Sentencia de 28 de noviembre de 2012. 